\title{
Peri-oestrous hormone profiles, embryonic survival and variation in embryonic development in gilts and primiparous sows
}

\author{
R. M. Blair, C. M. Coughlin, J. E. Minton and D. L. Davis* \\ Department of Animal Sciences and Industry, Kansas State University, Manhattan, KS 66506-0201, \\ USA
}

\begin{abstract}
The primary objective of this study was to determine whether embryo survival in gilts and primiparous sows is related to variations in the peri-oestrous profiles of oestradiol, progesterone and LH. A secondary objective of the present work was to compare embryo development and certain endocrine characteristics in gilts and primiparous sows. Sows $(n=6)$ and gilts $(n=6)$ were catheterized in the jugular vein on the day after weaning or on day 14 of the oestrous cycle, respectively. Additional females (one gilt and seven sows) were examined only for characteristics of embryonic development. Embryos were recovered on day 11.5-11.75 of gestation, and size and volume of individual embryos were recorded. Minimal differences were observed between sows and gilts for endocrine and embryo data. Embryo recovery was $71.38 \pm 4.77 \%$ based on the number of corpora lutea. However, endocrine differences were noted for pigs with high embryo survival ( $>71 \%$ recovery) compared with those with low survival. Peak oestradiol concentration occurred closer $(P<0.05)$ to the onset of oestrus in pigs with high embryo survival than in pigs with low embryo survival ( $3.3 \pm 4.6 \mathrm{~h}$ after oestrus versus $13.0 \pm 5.5 \mathrm{~h}$ before oestrus) and peak $\mathrm{LH}$ concentration occurred later $(P<0.05)$ after the onset of oestrus for pigs with high embryo survival. Peak oestradiol concentration tended $(P=0.07)$ to be higher in pigs with low embryo survival $\left(35.21 \pm 2.56 \mathrm{pg} \mathrm{ml}^{-1}\right)$ compared with pigs with high embryo survival $\left(28.17 \pm 2.14 \mathrm{pg} \mathrm{ml}^{-1}\right)$. Pigs with high embryo survival tended $(P=0.10)$ to have less variation in embryonic development than did those with low embryo survival $(40.76 \pm 7.14 \%$ versus $59.39 \pm 8.06 \%$, respectively). These data suggest that increased embryo survival and decreased embryonic diversity might be associated with a closer synchrony between the onset of the LH surge and oestrus and the peak concentration of oestradiol.
\end{abstract}

\section{Introduction}

Recent reports emphasize that the development of pig conceptuses to day 11 of pregnancy (day 0 , onset of oestrus) contributes to embryo losses by creating diversity of embryo development within litters (Pope et al., 1988, 1990; Xie et al., 1990a, b, c; Pope, 1992). Other workers (Corner, 1923; Perry and Rowlands, 1962) have indicated that substantial embryonic loss might occur before day 10 of pregnancy in pigs. Morphological and biochemical heterogeneity in follicular development is a feature of the peri-oestrous period in swine (Grant et al., 1989; Hunter et al., 1989; Hunter and Wiesak, 1990) and researchers have hypothesized that embryonic diversity and embryo mortality are the results of this follicular heterogeneity (Pope et al., 1990; Hunter and Wiesak, 1990; Pope, 1992).

These considerations led us to examine whether variations in the endocrine environment during the peri-oestrous period might be related to the events of early pregnancy that include

*Reprint requests.

Received 20 August 1993. embryo survival and diversity of embryonic development within females. To evaluate these possibilities, we determined characteristics of the oestrogen and LH surges during the peri-oestrous period and embryo survival to day 11 of gestation. We also evaluated the relationship between variation in conceptus development and survival of conceptuses to day II.

Stevenson and Davis (1984) found in one of two experiments that primiparous sows had lower percentages of fertilized eggs than did multiparous sows. This observation could be related to the finding that second litters may be no larger, or even smaller, than first litters (Hall et al., 1985; Gatel et al., 1987), although suppressed fertility for primiparous sows is not evident in all reports (Cromwell et al., 1989). Anomalies in the peri-oestrous endocrine environment might therefore be associated with fertilization failure or early embryonic death in pigs; however, no data are available that examine this possible association. The primary objective of the present study was to determine whether embryonic diversity and peri-oestrous endocrine events are associated with the proportion of ovulations represented by embryos on day 11 of gestation. A secondary objective was to evaluate embryonic diversity and Downloaded from Bioscientifica com at 04/26/2023 08:03:19AM 
peri-oestrous endocrine events in gilts and primiparous sows on day 11 of pregnancy.

\section{Materials and Methods}

\section{Animals}

Crossbred (Hampshire $\times$ Chester White $\times$ Yorkshire $\times$ Duroc) gilts $(n=6)$ and primiparous sows $(n=6)$ were fitted with jugular catheters (Takken and Williams, 1981) on day 14 of the oestrous cycle and on the day after weaning, respectively. Catheterized pigs were housed in individual pens to prevent perturbation of the catheters by other pigs. Both catheterized pigs, as well as other pigs (one gilt and seven sows) not sampled for endocrine data, were examined for differences in embryonic development. Gilts and sows were checked for oestrous behaviour three times a day (02:00, 10:00 and 18:00 h) with an intact boar, but were separated physically from boars at other times. Females were inseminated artificially with mixed semen from two boars 16,24 and $32 \mathrm{~h}$ after the observed onset of oestrus, as described by Rhodes et al. (1991).

\section{Collection of blood samples}

Blood samples were collected twice a day 06000 and 18:00 h) until day 17.5 of the oestrous cycle in gilts and until day 3.5 after weaning in sows. Thereafter, frequency of collection of blood samples was increased to intervals of $4 \mathrm{~h}$ until $24 \mathrm{~h}$ after the onset of oestrus. Blood samples were collected subsequently twice a day until day 5 after oestrus. Blood samples were stored overnight at $4^{\circ} \mathrm{C}$, centrifuged ( $1500 \mathrm{~g}$ for $20 \mathrm{~min}$ ), and then serum was collected. Serum was stored at $-20^{\circ} \mathrm{C}$ until analysed for oestradiol, progesterone, and LH by radioimmunoassay. Concentrations of progesterone were determined for samples taken at $06: 00$ and 18:00 h only, whereas all samples were analysed for oestradiol and $\mathrm{LH}$.

\section{Radioimmunoassays}

Progesterone. Serum concentrations of progesterone were determined using a direct radioimmunoassay in which antibody was coated onto polypropylene tubes (Diagnostic Products, Los Angeles, CA). As reported by the supplier, the antibody did not crossreact significantly with 16 other steroids tested (none greater than $2.4 \%$ crossreactivity). When $0.025,0.05$, $0.25,0.5,1,2.5,5$ and $10 \mathrm{ng}$ progesterone $\mathrm{ml}^{-1}$ were added to pig serum, $0.01,0.04,0.26,0.5,1.05,2.23,5.1$ and $9.4 \mathrm{ng}$ progesterone $\mathrm{ml}^{-1}$ were recovered in the assay, respectively. Serial dilutions of pig serum (50,100, 150 and $200 \mu \mathrm{l})$ showed parallelism to the standard curve. The assay was sensitive to $4.6 \mathrm{pg} \mathrm{ml}^{-1}$. The average intra-assay coefficient of variation was $3.33 \%$, and the interassay coefficient of variation was $10.92 \%$.

Oestradiol. A direct radioimmunoassay in which the antibody was coated onto polypropylene tubes (Diagnostic Products) was also used to determine serum concentrations of oestradiol. The antibody did not crossreact significantly with
49 other naturally occurring steroids and therapeutic drugs, as reported by the manufacturer (none greater than $1.8 \%$ crossreactivity). When $5,10,25,50$ and $100 \mathrm{pg}$ oestradiol ml were added to pig serum, 2.9, 9.9, 22.1, 52.3 and $102.1 \mathrm{pg}$ oestradiol $\mathrm{ml}^{-1}$ were recovered in the assay, respectively. Serial dilutions of pig serum $(50,100,150$ and $200 \mu$ l) showed parallelism to the standard curve. The assay was sensitive to $2.24 \mathrm{pg} \mathrm{ml}^{-1}$. The intra-assay and interassay coefficients of variation both averaged $4.2 \%$.

Luteinizing hormone. Concentrations of $\mathrm{LH}$ in pig serum were measured as described by Newton et al. (1987). The assay was sensitive to $0.24 \mathrm{ng} \mathrm{ml}^{-1}$. The average intra-assay coefficient of variation was $14.3 \%$, and the interassay coefficient of variation was $4.0 \%$.

\section{Embryo recovery}

Embryos were recovered surgically from all pigs on day 11.5-11.75 of gestation (day 0, onset of oestrus), according to the procedures of Rosenkrans et al. (1990). Anaesthesia was induced with a $5 \%$ solution of thiamylal sodium (Bio-tal: Intermountain Vet Supply, Kansas City, MO) and was maintained with methoxyflurane (Metofane: Pitman-Moore Inc., Mundelein, IL) and $1.0 \mathrm{l}$ oxygen $\min ^{-1}$. The ovaries and uterus were exteriorized by midventral laparotomy. The number of corpora lutea was recorded, and embryos were flushed from the uterus with $35 \mathrm{ml}$ Dulbecco's PBS (Gibco Laboratories, Grand Island, NY). The number, size and volume of individual embryos were recorded after recovery. Embryo volume was calculated assuming the embryo was a sphere or a prolate spheroid (Schact and Foote, 1978). To determine variations in embryonic development, the average deviation from the mean embryo volume was calculated within a litter as a percentage of the mean embryo volume.

\section{Statistical analyses}

Ovulation rate, embryo survival, embryonic development and characteristics of the oestradiol, progesterone and $\mathrm{LH}$ profiles were analysed using the General Linear Models procedure of SAS (SAS, 1988), with embryo survival (high versus low) and parity (gilt versus sow) included in the model statement. Procedure correlation of SAS was used to determine the statistical correlation between selected variables.

Plots of LH concentrations were used to identify the ovulatory surge of $\mathrm{LH}$, which was obvious in all pigs. Criteria were established to determine objectively the onset and the end of the LH surge. For each pig, the overall mean and SD for all LH values were calculated initially. Concentrations of $\mathrm{LH}$ greater than the overall mean plus one SD were defined to fall within the LH surge, and a new mean and SD were calculated after excluding those values within the $\mathrm{LH}$ surge. The new mean plus one SD was designated the LH baseline. The LH surge therefore began when concentrations first deviated from the baseline, and ended when LH returned to this baseline concentration. The highest concentration within the surge was designated as the peak.

Downloaded from Bioscientifica.com at 04/26/2023 08:03:19AM 
Table 1. Characteristics [mean \pm SEM (range)] of oestradiol, progesterone and LH secretion in pigs with high (>71\%) and low $(<71 \%)$ embryo recovery

\begin{tabular}{|c|c|c|c|c|c|}
\hline \multirow{2}{*}{$\begin{array}{l}\text { Characteristic } \\
\text { Number of pigs }\end{array}$} & \multicolumn{2}{|c|}{ High embryo survival } & \multicolumn{2}{|c|}{ Low embryo survival } & \multirow[t]{2}{*}{$P$ value } \\
\hline & \multicolumn{2}{|l|}{7} & \multicolumn{2}{|l|}{5} & \\
\hline \multicolumn{6}{|l|}{ Onset of oestrus to: } \\
\hline Peak [oestradiol] (h) & $3.3 \pm 4.6$ & $(-4-16)$ & $-13 \pm 5.5$ & $(-40-4)$ & $<0.1$ \\
\hline Peak [LH] (h) & $11 \pm 2$ & $(4-20)$ & $5 \pm 2$ & $(-4-12)$ & $<0.1$ \\
\hline Peak [oestradiol] ( $\mathrm{pg} \mathrm{ml}^{-1}$ ) & $28.17 \pm 2.14$ & $(23-36)$ & $35.21 \pm 2.56$ & $(26-44)$ & $<0.1$ \\
\hline Peak [LH] $\left(\right.$ ng ml $\left.^{-1}\right)$ & $7.01 \pm 1.18$ & $(3-13)$ & $6.35 \pm 1.41$ & $(4-10)$ & $>0.1$ \\
\hline Time from peak [oestradiol] to peak [LH] $(\mathrm{h})$ & $8 \pm 4$ & $(4-12)$ & $18 \pm 5$ & $(8-48)$ & $>0.1$ \\
\hline Duration of LH surge $(\mathrm{h})$ & $38 \pm 3$ & $(28-48)$ & $36 \pm 4$ & $(24-44)$ & $>0.1$ \\
\hline Time from onset of LH surge to peak [LH] (h) & $14 \pm 2$ & $(8-20)$ & $12 \pm 2$ & $(8-20)$ & $>0.1$ \\
\hline Time from peak $[\mathrm{LH}]$ to end of $\mathrm{LH}$ surge $(\mathrm{h})$ & $24 \pm 2$ & $(16-28)$ & $24 \pm 2$ & $(16-32)$ & $>0.1$ \\
\hline Onset of LH surge relative to oestrus (h) & $-3 \pm 2$ & $(-8-8)$ & $-7 \pm 3$ & $(-16-4)$ & $>0.1$ \\
\hline Onset of LH surge relative to peak [oestradiol] (h) & $-6 \pm 3$ & $(-8-4)$ & $6 \pm 4$ & $(-4-28)$ & $<0.1$ \\
\hline Time from onset of oestrus to [progesterone] $>2 \mathrm{ng} \mathrm{ml}^{-1}(\mathrm{~h})$ & $56 \pm 5$ & $(40-72)$ & $50 \pm 5$ & $(40-56)$ & $>0.1$ \\
\hline Time from peak [oestradiol] to [progesterone] $>2 \mathrm{ng} \mathrm{ml}^{-1}$ (h) & $59 \pm 5$ & $(48-64)$ & $69 \pm 5$ & $(56-96)$ & $>0.1$ \\
\hline Time from peak $[\mathrm{LH}]$ to [progesterone] $>2 \mathrm{ng} \mathrm{ml}^{-1}(\mathrm{~h})$ & $50 \pm 3$ & $(36-56)$ & $51 \pm 3$ & $(48-56)$ & $>0.1$ \\
\hline Time from onset of LH surge to [progesterone] $>2 \mathrm{ng} \mathrm{ml}^{-1}$ (h) & $64 \pm 3$ & $(56-72)$ & $63 \pm 3$ & $(56-68)$ & $>0.1$ \\
\hline
\end{tabular}

Similarly, the periovulatory rise in oestradiol was determined in plots from each pig, and the greatest concentration observed within this rise in oestradiol was designated as the peak.

\section{Results}

The number of corpora lutea was used as an estimate of ovulation rate, and mean embryo recovery for all pigs was $71.38 \pm 4.77 \%$. For statistical analyses, pigs with $>71 \%$ embryo recovery were therefore defined as having high embryo survival (mean embryo recovery $=86.61 \pm 2.66 \%$ ), whereas pigs with $<71 \%$ embryo recovery were defined as having low embryo survival (mean embryo recovery $=$ $52.77 \pm 5.53 \%$ ). The high embryo survival group consisted of seven sows and four gilts, whereas the low embryo survival group consisted of six sows and three gilts.

\section{Peri-oestrous hormone profiles}

Differences in the characteristics of the oestradiol and LH (but not progesterone) profiles were evident between pigs with high and low embryo survival (Table 1). Peak oestradiol concentration occurred later $(P<0.05)$ relative to the onset of oestrus in pigs with high embryo survival. On average, peak oestradiol concentration occurred after oestrus in pigs with high embryo survival and before oestrus in pigs with low embryo survival. Furthermore, for all animals, embryo survival increased as the interval from oestrus to peak oestradiol concentration increased $(r=0.64 ; P<0.05)$. Peak LH concentration occurred later $(P<0.05)$ after the onset of oestrus in pigs with high embryo survival compared with pigs with low embryo survival. This was consistent with a positive association between the duration of the interval from oestrus to peak LH concentration and embryo survival $(r=0.65 ; P<0.05$; Fig. 1a). An inverse relationship was also evident between the interval from oestrus to peak $\mathrm{LH}$ concentration and embryo volume $(r=-0.77 ; P<0.05)$. Peak oestradiol concentration tended $(P=0.07)$ to be higher in pigs with low embryo survival compared with pigs with high embryo survival. The onset of the LH surge differed $(P<0.05)$ for pigs with high versus low embryo survival, and occurred before peak oestradiol concentration in pigs with high embryo survival but around or after the time of peak oestradiol concentration in pigs with low embryo survival. For all animals, a negative association was evident between embryo survival and the interval from the onset of the LH surge to peak oestradiol concentration ( $r=-0.55 ; P=0.06$; Fig. $\mathrm{Ib}$ ).

The age of recovered embryos (measured as the interval from peak LH concentration to the time of embryo recovery) was greater (by $7 \mathrm{~h}$ ) for pigs with low versus high embryo survival, but the interval from peak $\mathrm{LH}$ concentration to embryo recovery did not affect $(P>0.30)$ the percentage of embryos recovered. Embryo age was positively correlated with embryo volume $(r=0.77 ; P<0.01)$ and average deviation of embryo volume $(r=0.81 ; P<0.01)$. However, embryo age had no effect $(P>0.1)$ on within-litter diversity of embryo development when included as a covariate in models testing the effects of high versus low embryo survival on embryo diversity.

No differences were evident in progesterone profiles between gilts and sows; however, differences were detected in oestradiol and LH profiles (Table 2). Peak LH concentration occurred nearer $(P<0.01)$ to the onset of oestrus in gilts than in sows, and the onset of the LH surge occurred earlier $(P<0.05)$ before oestrus in gilts than in sows. Peak oestradiol and LH concentrations both tended $(P=0.08$ and $P=0.11$, respectively) to be greater in gilts than in sows. Other characteristics of the oestradiol and $\mathrm{LH}$ profiles were similar in gilts and sows; however, gilts tended $(P=0.11)$ to have a greater interval from peak $\mathrm{LH}$ concentration to the end of the LH surge compared with sows.

Data on the duration of oestrus was available only for four sows and three gilts. It was evident that the duration of oestrus Downloaded from Bioscientifica.com at 04/26/2023 08:03:19AM 

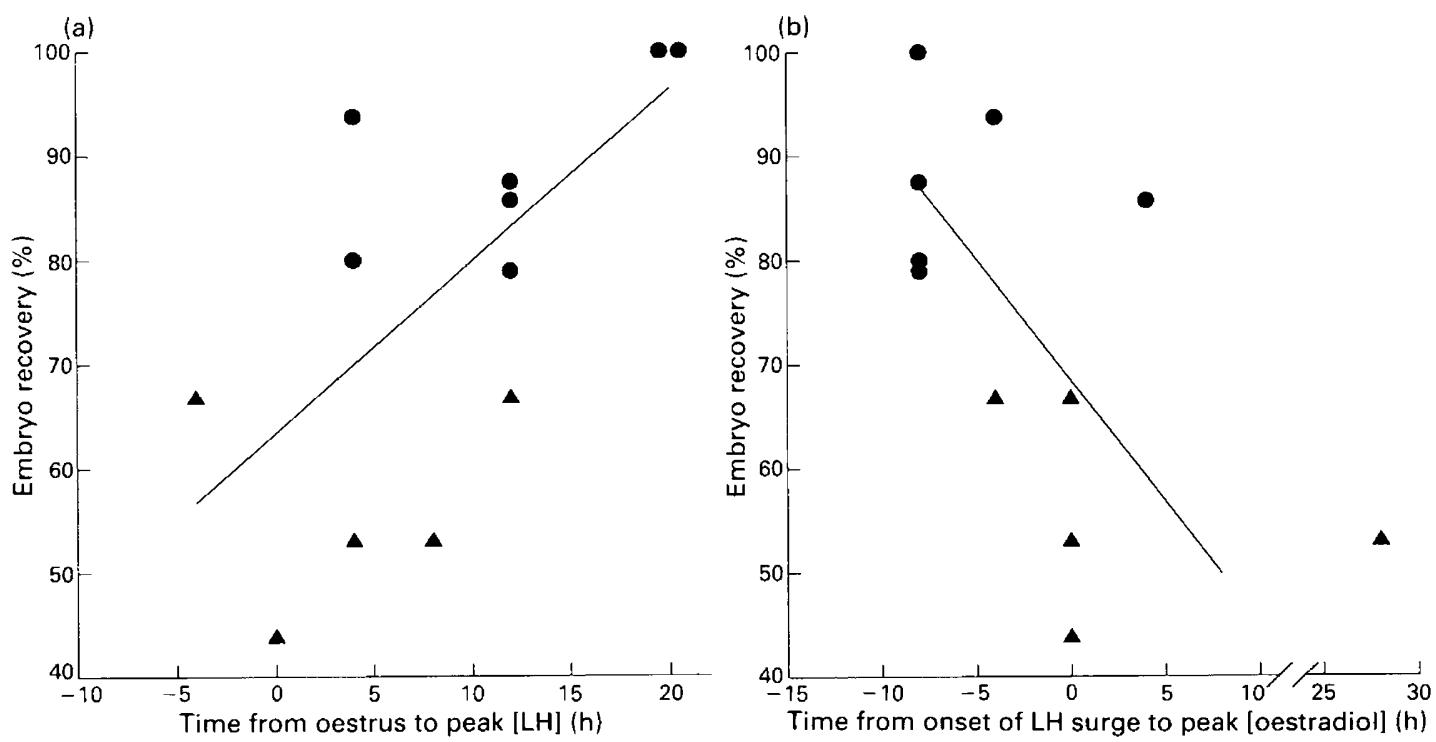

Fig. 1. Scatter plots of (a) the relationship between embryo survival and the interval from oestrus to peak [LH] $(r=0.65$; $P<0.05)$ and (b) the relationship between embryo survival and the interval from the onset of the LH surge to peak [oestradiol] $(r=-0.55 ; P=0.06)$. (O) Pigs with high embryo survival; $(\boldsymbol{\Delta})$ pigs with low embryo survival.

Table 2. Characteristics [mean \pm SEM (range)] of oestradiol, progesterone and LH secretion in gilts and sows

\begin{tabular}{|c|c|c|c|c|c|}
\hline Characteristic & \multicolumn{2}{|c|}{ Gilt } & \multicolumn{2}{|c|}{ Sow } & $P$ value \\
\hline Number of pigs & \multicolumn{2}{|c|}{6} & \multicolumn{2}{|c|}{6} & \\
\hline \multicolumn{6}{|l|}{ Onset of oestrus to: } \\
\hline Peak [oestradiol] (h) & $-5 \pm 5$ & $(-12-0)$ & $-5 \pm 5$ & $(-40-16)$ & $>0.1$ \\
\hline Peak [LH] (h) & $3 \pm 2$ & $(-4-12)$ & $13 \pm 2$ & $(8-20)$ & $<0.1$ \\
\hline Peak [oestradiol] $\left(\mathrm{pg} \mathrm{ml}^{-1}\right)$ & $35.01 \pm 2.29$ & $(23-44)$ & $28.37 \pm 2.43$ & $(22-36)$ & $<0.1$ \\
\hline Peak [LH] (ng ml $\left.{ }^{-1}\right)$ & $8.36 \pm 1.26$ & $(7-10)$ & $5.00 \pm 1.33$ & $(3-13)$ & $>0.1$ \\
\hline Time from peak [oestradiol] to peak [LH] (h) & $8 \pm 4$ & $(4-12)$ & $18 \pm 5$ & $(4-48)$ & $>0.1$ \\
\hline Duration of LH surge (h) & $39 \pm 3$ & $(36-44)$ & $35 \pm 3$ & $(24-48)$ & $>0.1$ \\
\hline Time from onset of $\mathrm{LH}$ surge to peak $[\mathrm{LH}](\mathrm{h})$ & $12 \pm 2$ & $(8-20)$ & $14 \pm 2$ & $(8-20)$ & $>0.1$ \\
\hline Time from peak $[\mathrm{LH}]$ to end of LH surge $(\mathrm{h})$ & $27 \pm 2$ & $(24-32)$ & $22 \pm 2$ & $(16-28)$ & $>0.1$ \\
\hline Onset of $\mathrm{LH}$ surge relative to oestrus $(\mathrm{h})$ & $-9 \pm 2$ & $(-16-[-4])$ & $-0.5 \pm 2$ & $(-12-8)$ & $<0.1$ \\
\hline Onset of LH surge relative to peak [oestradiol] (h) & $-4 \pm 3$ & $(-8-0)$ & $5 \pm 3$ & $(-8-28)$ & $>0.1$ \\
\hline Time from onset of oestrus to [progesterone] $>2 \mathrm{ng} \mathrm{ml}^{-1}(\mathrm{~h})$ & $53 \pm 5$ & $(48-60)$ & $53 \pm 5$ & $(40-72)$ & $>0.1$ \\
\hline Time from peak [oestradiol] to [progesterone] $>2 \mathrm{ng} \mathrm{ml}^{-1}(\mathrm{~h})$ & $58 \pm 5$ & $(48-64)$ & $70 \pm 5$ & $(56-96)$ & $>0.1$ \\
\hline Time from peak $[\mathrm{LH}]$ to [progesterone] $>2 \mathrm{ng} \mathrm{ml}^{-1}(\mathrm{~h})$ & $49 \pm 3$ & $(36-56)$ & $52 \pm 3$ & $(48-56)$ & $>0.1$ \\
\hline Time from onset of LH surge to [progesterone] $>2 \mathrm{ng} \mathrm{ml}^{-1}(\mathrm{~h})$ & $62 \pm 3$ & $(56-68)$ & $65 \pm 3$ & $(60-72)$ & $>0.1$ \\
\hline
\end{tabular}

increased with an increase in the interval from observed oestrus to peak $\mathrm{LH}$ concentration $(r=0.83 ; P<0.05)$. The timing of the peak in LH concentration relative to the onset of observed oestrus therefore appears to be involved in determining the duration of oestrus.

\section{Embryo development}

Recovered embryos ranged in size from very small spherical blastocysts to blastocysts that were ovoid or tubular, but none of the embryos had elongated to the filamentous stage of development. Ovulation rate, embryo survival and embryo development were similar between gilts and sows (Table 3).

No differences in ovulation rate and embryo volume were evident between pigs with high and low embryo survival; however, pigs with high embryo survival tended $(P=0.10)$ to vary less in embryonic development (expressed as the average deviation of embryo volume as a percentage of mean embryo volume) compared with pigs with low embryo survival. Evaluation of the data from all animals supports this association because there was a negative correlation between embryo survival and the within-litter percentage deviation in embryo development $(r=-0.79, P=0.0001)$. 
Table 3. Embryo development [mean \pm SEM (range)] on day 11.5-11.75 in pigs with high ( $>71 \%$ ) versus low (<71\%) embryo recovery and in gilts versus sows

\begin{tabular}{|c|c|c|c|c|c|c|}
\hline \multirow[b]{2}{*}{ Characteristic } & \multicolumn{3}{|c|}{ Embryo survival } & \multicolumn{3}{|c|}{ Parity } \\
\hline & High & Low & $P$ value & Gilt & Sow & $P$ value \\
\hline Number of pigs & 11 & 9 & & 7 & 13 & \\
\hline Embryo recovery (\%) & $\begin{array}{c}86.61 \pm 2.66 \\
(75.00-100.00)\end{array}$ & $\begin{array}{c}52.77 \pm 5.53 \\
(13.64-66.67)\end{array}$ & $<0.1$ & $\begin{array}{c}69.26 \pm 5.17 \\
(43.75-93.75)\end{array}$ & $\begin{array}{c}70.00 \pm 3.76 \\
(13.64-100.00)\end{array}$ & $>0.1$ \\
\hline Ovulation rate & $\begin{array}{l}15.88 \pm 0.82 \\
\quad(13-23)\end{array}$ & $\begin{array}{c}17.25 \pm 0.92 \\
(15-22)\end{array}$ & $>0.1$ & $\begin{array}{l}15.88 \pm 0.99 \\
(15-17)\end{array}$ & $\begin{array}{c}17.25 \pm 0.72 \\
\quad(13-23)\end{array}$ & $>0.1$ \\
\hline Embryo volume $\left(\mathrm{mm}^{3}\right)$ & $\begin{array}{l}403.04 \pm 118.75 \\
(11.58-1099.26)\end{array}$ & $\begin{array}{l}368.12 \pm 133.96 \\
(72.57-1041.03)\end{array}$ & $>0.1$ & $\begin{array}{c}414.43 \pm 144.70 \\
(72.57-649.88)\end{array}$ & $\begin{array}{l}356.72 \pm 105.40 \\
(11.58-1099.26)\end{array}$ & $>0.1$ \\
\hline $\begin{array}{l}\text { Average deviation of } \\
\text { embryo volume }\left(\mathrm{mm}^{3}\right)^{\mathrm{a}}\end{array}$ & $\begin{array}{c}162.45 \pm 50.41 \\
(5.31-486.53)\end{array}$ & $\begin{array}{l}189.84 \pm 56.88 \\
(57.83-393.09)\end{array}$ & $>0.1$ & $\begin{array}{l}180.13 \pm 61.43 \\
(57.83-298.66)\end{array}$ & $\begin{array}{c}172.16 \pm 44.75 \\
(5.31-486.53)\end{array}$ & $>0.1$ \\
\hline $\begin{array}{l}\text { Average deviation as } \% \text { of } \\
\text { mean embryo volume }\end{array}$ & $\begin{array}{c}40.76 \pm 7.14 \\
(22.15-60.70)\end{array}$ & $\begin{array}{c}59.39 \pm 8.06 \\
(26.55-124.74)\end{array}$ & 0.10 & $\begin{array}{l}50.14 \pm 8.70 \\
(22.15-79.69)\end{array}$ & $\begin{array}{c}50.01 \pm 6.34 \\
(24.47-124.74)\end{array}$ & $>0.1$ \\
\hline
\end{tabular}

aThe mean conceptus volume for each litter was determined and the absolute value of the deviation from the mean determined for each conceptus. The average deviation within each litter was used as a measure of the diversity in size within the litter.

${ }^{b}$ Calculated as in footnote ${ }^{a}$, except that each deviation was converted to a percentage of the mean conceptus volume for the litter.

\section{Discussion}

In the present study, ovulation rate, embryo diversity and embryo survival were similar between gilts and sows, indicating that fertility was not reduced in primiparous sows. In contrast, Stevenson and Davis (1984) and Gatel et al. (1987) reported that fertilization rate is lower and that litter size declines at the second farrowing. Data from our study indicate that the population of primiparous sows used had neither lower fertility nor fecundity than did gilts.

The time of the pre-ovulatory surge of $\mathrm{LH}$ in pigs varies from $32 \mathrm{~h}$ before to $24 \mathrm{~h}$ after the onset of oestrus (Tilton $e$ al., 1982; Ziecik et al., 1982; Helmond et al., 1986). Results in the present study fell within this same range; that is, $\mathrm{LH}$ reached a peak from $4 \mathrm{~h}$ before to $20 \mathrm{~h}$ after the onset of oestrus.

Previous research suggests that heterogeneity of follicular development results in embryonic diversity and the subsequent loss of the less-developed embryos within a litter (Pope et al., 1990; Pope, 1992). The growth and development of tertiary follicles is under the influence of both FSH and $\mathrm{LH}$; and LH has a key role in the initiation of follicular development and ovulation (Britt et al., 1985). Thus, alterations in the secretion of $\mathrm{LH}$, oestradiol and progesterone may be involved in the degree of embryonic diversity observed within litters.

In the study reported here, differences were noted in the $\mathrm{LH}$ and oestradiol profiles between pigs with high versus low embryo survival. Xie et al. (1990c) indicated that disparity in the time of ovulation (Pope et al., 1988) and zygotic maturation (Xie et al., 1990a) might be the result of skewed follicular development, in which most follicles were more developed than the minority $21-34 \mathrm{~h}$ after the onset of oestrus. Grant et al. (1989) suggested that a small group of follicles on day 18 of the oestrous cycle secretes oestradiol sooner than do other follicles and induces the ovulatory surge of LH. This series of events would result in the ovulation of follicles at different maturational stages, and could contribute to diversity in embryonic development. In contrast, other studies have reported that the duration of ovulation, as measured by transrectal ultrasonography, is unrelated to embryonic diversity (Soede et al., 1992; Soede and Kemp, 1993) when judging the number of nuclei approximately 5 days after ovulation. However, variation in embryo size in pigs appears to be greatest on days 11 and 12 of gestation (Pusateri et al., 1990) and that corresponds to the stage of development evaluated in the present study.

The interval from oestrus to the time of peak $\mathrm{LH}$ concentration also affects embryo development. Embryo volumes were smaller in pigs that had a later $\mathrm{LH}$ peak relative to oestrus. These embryos would therefore have been ovulated later and thus were younger. The interval from oestrus to peak $\mathrm{LH}$ concentration differed by approximately $6 \mathrm{~h}$ between females with high versus low embryo survival. It is unlikely that this small difference would account for differences in embryo survival. Cardenas and Pope (1993) demonstrated that mating gilts before ovulation or after ovulation, a difference of 11-19 h, did not affect embryo survival or embryo diversity upon recovery of the embryos.

In the study reported here, positive correlations were evident between the interval from peak $\mathrm{LH}$ concentration to the moment of embryo recovery and embryo development, as well as between embryo development and timing of first insemination relative to peak $\mathrm{LH}$ concentration; however, these intervals were not related to embryo diversity expressed as a percentage of the mean embryo size for each female. The interval from peak LH concentration to embryo recovery was $7 \mathrm{~h}$ shorter for pigs with high versus low embryo survival. This is attributable to the later LH surge in pigs with high survival embryos. While embryo losses probably accumulate with increased time after ovulation, it is unlikely that $7 \mathrm{~h}$ is a long enough interval to detect increased embryonic loss. The effects of the time of the LH surge are therefore probably related to the synchrony of events around oestrus rather than to the slightly increased interval to embryo recovery. 
Hunter et al. (1993) indicated that the onset of the $\mathrm{LH}$ surge occurred later relative to oestrus in Meishan pigs, a breed known for its prolificacy, than in Large White hybrid gilts. In Meishan gilts, the onset of the LH surge occurred approximately $0.5 \mathrm{~h}$ after the onset of oestrus, whereas the onset of the LH surge occurred approximately $32 \mathrm{~h}$ before the onset of oestrus in Large White gilts. These data suggest that a later LH surge may be important for increased embryo survival in Meishan gilts. Meishan gilts also exhibited a shorter interval between the onset of oestrus and the peak plasma concentration of oestradiol compared with Large White hybrid gilts (Hunter et al., 1993). Although the time from the onset of oestrus to the onset of the LH surge did not differ in the present study between pigs with high and low embryo survival, those with high embryo survival exhibited a shorter interval between the onset of oestrus and the time of peak oestradiol concentration as well as a longer interval from the onset of oestrus to peak $\mathrm{LH}$ concentration. Hunter et al. (1993) also reported that peak LH and oestradiol concentrations, duration of the $\mathrm{LH}$ surge, and the interval from peak oestradiol concentration to the onset of the $\mathrm{LH}$ surge were similar in Meishan and Large White gilts. The comparison of high versus low embryo survival in the present study produced similar results, with the exception that the onset of the LH surge occurred before the peak oestradiol concentration in pigs with high embryo survival and after the peak oestradiol concentration in pigs with low embryo survival.

Apparently, the peri-oestrus profiles of LH and oestradiol exhibit different characteristics in pigs with high versus low embryo survival. However, it remains unclear whether these differences are related to heterogeneity of follicular development and ovulation or affect the oviductal or uterine environments. Measurements of embryo losses at this early stage also include technical failures in embryo recovery. However, the endocrine characteristics measured should not influence the ability to recover viable embryos. Embryo recovery should therefore provide an acceptable estimate of embryo survival. It is also possible that these endocrine changes are not causally related to embryo survival. However, these possibilities should be investigated.

In our study, pigs with high embryo survival on day 11.5-11.75 of gestation tended to exhibit less variation in embryonic development than did pigs with low embryo survival. Embryo losses in our experiment might be due to fertilization failures or embryo death before day 11. Litters with more embryo variation might experience more losses after day 13 of gestation, as reported by Pope et al. (1986).

In conclusion, results of the present study suggest that a closer synchrony among the peak oestradiol concentration, the onset of the LH surge and oestrus is associated with reduced embryo diversity and higher embryo survival before implantation. It remains to be determined whether these endocrine variations directly affect embryonic diversity and embryo survival.

The authors appreciate the assistance of Y. Zhang, P. Groothuis, E. Jacob, M. Krause, T. Prothe and J. Velte with the blood sampling, feeding and care of the animals; and D. J. Bolt, USDA Animal Hormone Program, for reagents for the LH assay. This research was supported by the Kansas Agricultural Experiment Station, Contribution No. 93-570-J.

\section{References}

Britt JH, Armstrong JD, Cox NM and Esbenshade KL (1985) Control of follicular development during and after lactation in sows Joumal of Reproduction and Fertility Supplement 33 37-54

Cardenas H and Pope WF (1993) Effect of time of mating relative to ovulation on morphological diversity of swine blastocysts Biology of Reproduction 49 1015-1018

Corner GW (1923) The problem of embryonic pathology in mammals, with observations upon intrauterine mortality in the pig The American Journal of Anatomy 31 523-545

Cromwell GL, Hall DD, Clawson AJ, Combs GE, Knabe DA, Maxwell CV, Noland PR, Orr DE and Prince TJ (1989) Effects of additional feed during late gestation on reproductive performance of sows: a cooperative study journal of Animal Science 67 3-14

Gatel F, Castaing I and Lucbert J (1987) Changes in productivity and culling rate according to pregnancy feed intake and litter parity Livestock Production Science $17 \quad 247-261$

Grant SA, Hunter MG and Foxcroft GR (1989) Morphological and biochemical characteristics during the ovarian follicular development in the pig Journal of Reproduction and Fertility 86 171-183

Hall DD, Cromwell GL, Prince TJ, Knabe DA, Clawson AJ, Maxwell CV, Noland PR, Orr DE and Combs GE (1985) Depletion of body fat reserves: an explanation for decreased second parity prolificacy in sows Joumal of Animal Science 61 (Supplement I) 316

Helmond F, Aarnink A and Oodenaarden C (1986) Periovulatory hormone profiles in relation to embryonic development and mortality in pigs. In Embryonic Mortality in Farm Animals pp 119-125 Eds JM Sreenan and MG Diskin. Martinus Nijhoff Publishers, Dordrecht

Hunter MG and Wiesak T (1990) Evidence for and implications of follicular heterogeneity in pigs Journal of Reproduction and Fertility Supplement $\mathbf{4 0}$ 163-177

Hunter MG, Grant SA and Foxcroft GR (1989) Histological evidence for heterogeneity in the development of preovulatory pig follicles Journal of Reproduction and Fertility 86 165-170

Hunter MG, Biggs C, Foxcroft GR, McNeilly AS and Tilton JE (1993) Comparisons of endocrinology and behavioural events during the periovulatory period in Meishan and Large-White hybrid gilts Journal of Reproduction and Fertility $97 \quad 475-480$

Newton EA, Stevenson JS, Minton JE and Davis DL (1987) Endocrine changes before and after weaning in response to boar exposure and altered suckling in sows Journal of Reproduction and Fertility 81 599-609

Perry JS and Rowlands IW (1962) Early pregnancy in the pig Journal of Reproduction and Fertility 4 175-188

Pope WF (1992) Embryogenesis recapitulates oogenesis in swine Proceedings of the Society for Experimental Biology and Medicine 199 273-281

Pope WF, Lawyer MS, Nara BS and First NL (1986) Effect of asynchronous superinduction on embryo survival and range of blastocyst development in swine Biology of Reproduction 35 133-137

Pope WF, Wilde MH and Xie S (1988) Effect of electrocautery of nonovulated day 1 follicles on subsequent morphological variation among day 11 porcine embryos Biology of Reproduction 39 882-887

Pope WF, Xie S, Broermann DM and Nephew KP (1990) Causes and consequences of early embryonic diversity in pigs Joumal of Reproduction and Fertility Supplement 40 251-260

Pusateri AE, Rothschild MF, Warner CM and Ford SP (1990) Changes in morphology, cell number, cel! size, and cellular estrogen content of individual littermate pig conceptuses on days 9 to 13 of gestation Journal of Animal Science 68 3727-3735

Rhodes MT, Davis DL and Stevenson JS (1991) Flushing and altrenogest affect litter traits in gilts Journal of Animal Science 69 34-40

Rosenkrans CF, Jr, Paria BC, Davis DL and Milliken G (1990) In vitro synthesis of prostaglandin $\mathrm{E}$ and $\mathrm{F}_{2 \alpha}$ by pig endometrium in the presence of estradiol, catechol estrogen and ascorbic acid Journal of Animal Science 68 435-443

SAS (1988) SAS/STAT User's Guide (Release 6.03). SAS Institute Inc, Cary, NC

Schact CJ and Foote RH (1978) Progesterone induced asynchrony and embryo mortality in rabbits Biology of Reproduction 19 534-539 Downloaded from Bioscientifica.com at 04/26/2023 08:03:19AM 
Soede NM and Kemp B (1993) In synchronized pigs, the duration of ovulation is not affected by insemination and is not a determinant for early embryonic diversity Theriogenology 39 1043-1053

Soede NM, Noordhuizen JPTM and Kemp B (1992) The duration of ovulation in pigs, studied by transrectal ultrasonography, is not related to early embryonic diversity Theriogenology 38 653-666

Stevenson JS and Davis DL (1984) Influence of reduced litter size and daily litter separation on fertility of sows at 2 to 5 weeks postpartum Journal of Animal Science 59 284-293

Takken A and Williams KC (1981) A simplified procedure for long-term catheterisation of the anterior vena cava in adult pigs Australian Veterinary Joumal 57 17-20

Tilton JE, Foxcroft GR, Ziecik AJ, Coombs SL and Williams GL (1982) Time of the preovulatory surge in the gilt and sow relative to the onset of behavioral estrus Theriogenology 18 227-236
Xie S, Broermann DM, Nephew KP, Bishop MD and Pope WF (1990a) Relationship between oocyte maturation and fertilization on zygotic diversity in swine Journal of Animal Science 68 2027-2033

Xie S, Broermann DM, Nephew KP, Geisert RD and Pope WF (1990b) Ovulation and early embryogenesis in swine Biology of Reproduction 43 236-240

Xie S, Broermann DM, Nephew KP, Ottobre JS, Day ML and Pope WF (1990c) Changes in follicular endocrinology during final maturation of porcine oocytes Domestic Animal Endocrinology 7 75-82

Ziecik A, Krzymowska H and Tilton JE (1982) Porcine LH levels during the estrous cycle, gestation, parturition and early lactation Journal of Animal Science 54. 1221-1225 